\title{
Early development and substrate twine selection for the cultivation of Sargassum muticum (Yendo) Fensholt under laboratory conditions
}

\author{
Hau Nhu Le ${ }^{1,2} \cdot$ Adam D. Hughes $^{1} \cdot$ Philip D. Kerrison ${ }^{1}$ \\ Received: 7 August 2017 / Revised and accepted: 15 March 2018 / Published online: 23 April 2018 \\ (C) The Author(s) 2018
}

\begin{abstract}
The phaeophyte macroalgae Sargassum muticum is under investigation as a cultivation crop within its native range in SE Asia, alongside other members of the Sargassum genus. During the critical hatchery phase, germlings are grown to $\geq$ several millimeters ready for outplanting. By optimising the growth medium and twine substrate used for the germling attachment, hatcheries can become more efficient and cost-effective. An 8-week replicated laboratory experiment investigated these factors. It found that adding $0.125 \mathrm{~mL} \mathrm{~L}^{-1}$ of saturated germanium dioxide during the first week increased mean germling size by $23 \%(p<0.005)$, whereas additional nutrients in the form of $\mathrm{F} / 2$ medium made no difference $(p>0.05)$. Six twine substrates were also tested: jute, cotton, polyamide/cotton, polyester, polyvinyl alcohol and polypropylene. Sargassum muticum grew similarly well on all, although attachment success during the first week was highest on the rougher natural fibres, particularly jute. A negative density-dependent effect of germling density on growth was seen across all materials, with the highest growth seen on the materials with the lowest germling density. Jute is recommended as a highly suitable substrate for hatchery cultivation in this species, although the initial density should be carefully controlled to prevent intraspecific competition.
\end{abstract}

Keywords Sargassum muticum $\cdot$ Phaeophyta $\cdot$ Hatchery $\cdot$ Nutrient $\cdot$ Cultivation $\cdot \mathrm{GeO}_{2} \cdot$ Twine

\section{Introduction}

Sargassum muticum is native to coastal China, Japan and Korea, where it can form extensive monospecific or mixed sub-littoral canopies (Yoshida 1983). These canopies provide numerous ecosystem services such as coastal protection, primary production, nutrient cycling and spawning, nursery and feeding areas for species of commercial importance (CostonClements et al. 1991; Tsukidate 1992; Al-Hafedh et al. 2015). Sargassum sp. stands are harvested for food, traditional medicine, feed, fertiliser and chemical products (Sohn 1993; Hong

Philip D. Kerrison

Philip.kerrison@sams.ac.uk

Hau Nhu Le

Lenhuhau2003@yahoo.com

Adam D. Hughes

Adam.hughes@sams.ac.uk

1 Scottish Association for Marine Science (SAMS), Scottish Marine Institute, Dunbeg, Argyll 1QA, UK

2 Nha Trang Institute of Technology and Application (NITRA), Vietnam Academy of Science and Technology (VAST), 2 Hung Vuong Street, Nha Trang, Vietnam et al. 2007), which have led to widespread overexploitation. This problem is exacerbated by other anthropogenic interferences such as pollution and land reclamation (Mata et al. 2016).

To ensure a continued supply and provide seed stock for the restoration of natural beds, cultivation methods are under development for many Sargassaceae species (Titlyanov et al. 2012; Redmond et al. 2014; Yoon et al. 2014). Sargassum muticum is currently cultivated within its native range in SE Asia (Cao et al. 2008; Liu et al. 2013), along with a number of its relatives including Sargassum fusiforme (Pang et al. 2005), Sargassum fulvellum (Hwang et al. 2006), Sargassum horneri (Pang et al. 2009), Sargassum naozhouense (Xie et al. 2013), Sargassum thunbergii (Zhao et al. 2008) and Sargassum vachellianum (Chai et al. 2014). Germlings are initially attached to twines or fabrics that may be grown within the hatchery for 3-5 months before they are outplanted into the sea (Redmond et al. 2014). Optimising the juvenile growth and development within the hatchery will reduce costs and maximise efficiency.

Sargassum muticum is considered to be one of the world's most successful invasive seaweeds (Denny 1988). Due to its wide physicochemical tolerance for growth and reproduction combined with varied dispersal methods, it is an opportunistic 
space-grabber (Fletcher and Fletcher 1975; Kerrison and Le 2016). These characteristics have allowed it to spread rapidly around the Atlantic coast of North America and Europe following accidental introductions (Critchley et al. 1983). It now ranges from the cold waters of southern Alaska and Norway to the warmer waters of Mexican Pacific and the Mediterranean (Cheang et al. 2010). In some locations, the invasion has displaced native species of macroalgae or seagrass by forming dense stands which overgrow and outcompeting the native flora (Fletcher and Fletcher 1975; Denny 1988; Callow et al. 2000; Bitton et al. 2006), whilst in other cases, little or no impact is seen (Dexter et al. 1975).

It has previously been determined that egg release and germling production are maximised at $20^{\circ} \mathrm{C}$ and 50 $100 \mu \mathrm{mol}$ photons $\mathrm{m}^{-2} \mathrm{~s}^{-1}$ (Kerrison and Le 2016). Furthermore, a 3-min treatment of $0.5 \%$ potassium iodide with $0.38 \%$ sodium hypochlorite can be used to remove grazing epibionts from either adults or 6-week-old germlings, with little physiological impact (Kerrison et al. 2016a). In other members of the Sargassaceae and kelp such as Saccharina latissima, there is ongoing research to optimise the hatchery phase through manipulation of the nutrient growth medium (Kerrison et al. 2016b) and the addition of the diatom inhibiting compound $\left(\mathrm{GeO}_{2}\right)$ germanium dioxide (Shea and Chopin 2007). The use of $\mathrm{GeO}_{2}$ is considered equally applicable to the cultivation of $S$. muticum, and so, it has been used previously during Sargassum sp. cultivation experiments (Fletcher and Fletcher 1975; Huggett et al. 2009; Heydt et al. 2012), although the benefit has not be validated or the dosage optimised.

It is known that $S$. muticum requires a hard surface for attachment of the holdfast. This includes anything from shells or pebbles up to bedrock or man-made structures (Fletcher and Fletcher 1975; Norton 1977; Critchley et al. 1983). Settling germlings are coated in extensive mucilage which is reported to adhere to whatever substrate they encounter, with the attachment tenacity increasing over time as the adhesive is secreted by the developing rhizoid mass (Norton 1980; Norton and Fetter 1981). A rugose surface is most favourable, allowing greatest retention of young germlings when exposed to water motion (Malm et al. 2003). The species also has the unusual ability to colonise soft substrata; following the initial settlement, the developing adult is partially buried allowing to remain secured, despite buoyancy provided by internal gas bladders (Strong et al. 2006).

Various strings are used for the cultivation of Sargassum spp., including mixes of polyamide (PA), cotton and polypropylene (PP) (Hwang et al. 2006; Zhao et al. 2008; Pang et al. 2009; Xie et al. 2013). However, the authors are not aware of any study comparing the suitability of different synthetic or natural twine. The utilisation of the best twine may allow the optimal hatchery development of Sargassum spp. germlings.
The first aim of this study was to determine whether the hatchery development of juvenile $S$. muticum could be optimised by the addition of nutrients or dosing with $\mathrm{GeO}_{2}$. The second aim was to compare the attachment and growth of S. muticum on six commercially available twines, to determine which was best for the cultivation of this genus.

\section{Materials and methods}

\section{Algal materials}

Fertile specimens of Sargasum muticum were collected in August 2014, at $0.5-1.0 \mathrm{~m}$ below chart datum from Great Cumbrae Island, Western Scotland (Fig. 1; $55^{\circ} 45.211 \mathrm{~N}$, $004^{\circ} 54.070 \mathrm{~W}$ ), based on observations made in previous reports (Harries et al. 2007). Cool boxes of natural seawater were used to transport these to the Scottish Association for Marine Science (SAMS), Oban, within $3 \mathrm{~h}$. Selected thalli were healthy and yellowish-brown in appearance with swollen receptacles which had no obvious shedding. These were gentled cleaned of obvious epiphytic macroalgae and animals using a camel-bristled brush then weighted and submerged within outdoor 70-L aerated tanks of sand-filtered seawater under natural condition $\left(13-16{ }^{\circ} \mathrm{C}, 100-200 \mu\right.$ mol photons $\left.\mathrm{m}^{-2} \mathrm{~s}^{-1}\right)$.

\section{Liberation and collection of germlings}

Within 2 weeks, of incubation in outdoor tanks, receptacles had matured and begun to shed in the typical acropetal sequence (Kerrison and Le 2016). Receptacle-bearing branches from $\sim 1.5 \mathrm{~kg}$ were excised, rinsed and then incubated within two indoor 70-L tanks of sand-filtered seawater $\left(20-22{ }^{\circ} \mathrm{C}\right.$, 50-80 $\mu \mathrm{mol}$ photons $\mathrm{m}^{-2} \mathrm{~s}^{-1}$ ) for $36 \mathrm{~h}$. Preliminary trials showed that after $36 \mathrm{~h}$ under these conditions $\sim 70 \%$ of all eggs had detached from the parent branches and sink vertically, adhering to the available substrate as described in Kerrison and Le (2016). Gentle brushing was used to detach mature eggs and germlings from the bottom of the tanks and from the receptacles. These were then collected using a $125-\mu \mathrm{m}$ filter and washed and re-filtered several times in Tyndallised seawater (Kawachi and Noël 2005). The size and number of zygotes were then measured under a light microscope (ZeissAxioskop, Germany) and photographed with a connected camera (Canon EOS1100D, Taiwan).

\section{Germling settlement}

A tank with a bottom area of $0.5 \mathrm{~m}^{2}$ was filled with $10 \mathrm{~L}$ of Tyndallised seawater enriched with $\mathrm{F} / 2$ medium (Guillard 1975) without silicate $(\mathrm{F} / 2-\mathrm{Si})$ and $0.125 \mathrm{mg} \mathrm{L}^{-1} \mathrm{GeO}_{2}$ to prevent diatom growth (Markham and Hagmeier 1982; 
Fig. 1 Invasive Sargassum muticum adults were collected from Great Cumbrae, UK (a) in August 2014, where they form subtidal canopies (b)
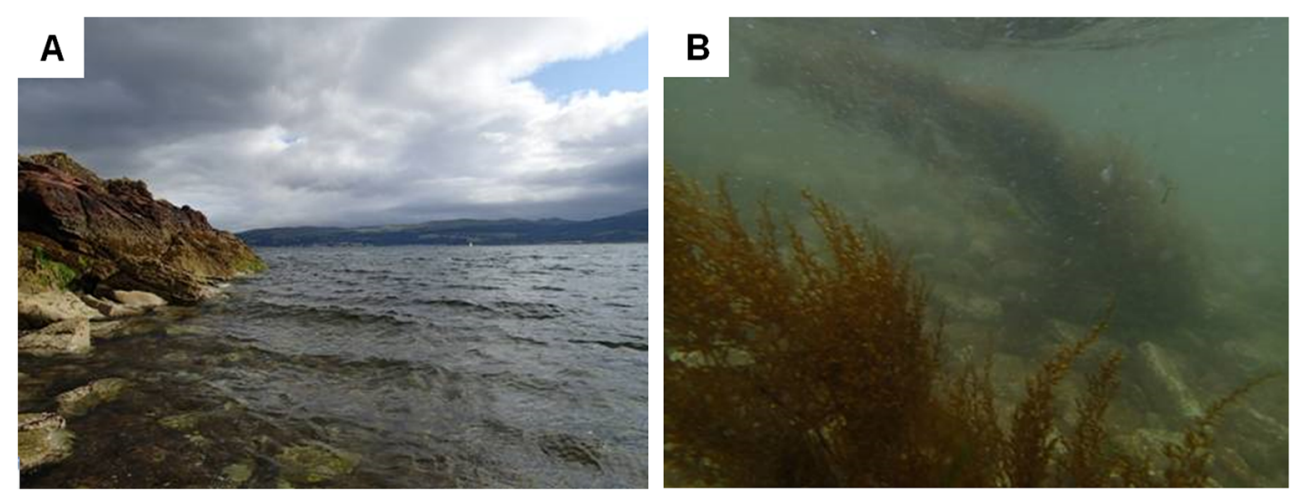

Kerrison et al. 2016b). Glass slides $(20 \times 38 \mathrm{~cm})$, bearing a $\sim 24 \times 24$-mm area of wrapped settlement twine, were distributed on the bottom of the tank (Fig. 2). The twines were jute, cotton, PA/cotton, polyester (PES), polyvinyl alcohol (PVA) and PP (Fig. 3). These were soaked overnight in 5\% Decon90 (Decon Laboratories Ltd, UK), rinsed thoroughly with distilled water and dried at $40{ }^{\circ} \mathrm{C}$. The zygote suspension was then sprayed evenly over the water surface and $2 \mathrm{~h}$ was allowed for the non-motile zygotes to settle to the bottom. This resulted in a settlement density of $240 \pm 14 \mathrm{zy}-$ gotes $\mathrm{cm}^{-2}$ (mean \pm S.D., $\left.n=10\right)$ and a germination rate of $92 \%$.

\section{Incubation experiment}

Settlement slides were then transferred into tubs containing $400 \mathrm{~mL}$ of seawater medium with transparent lids (Fig. 4). The tubs were then incubated in triplicate at $25 \pm 0.5^{\circ} \mathrm{C}$ and under 20-150 $\mu \mathrm{mol}$ photons $\mathrm{m}^{-2} \mathrm{~s}^{-1} ; 12: 12 \mathrm{~h}$ light:dark cycle. This irradiance variation has a little significant impact on S. muticum growth (Kerrison PD, Le HN, Hughes AD (unpublished results)). The temperature was maintained using controllers

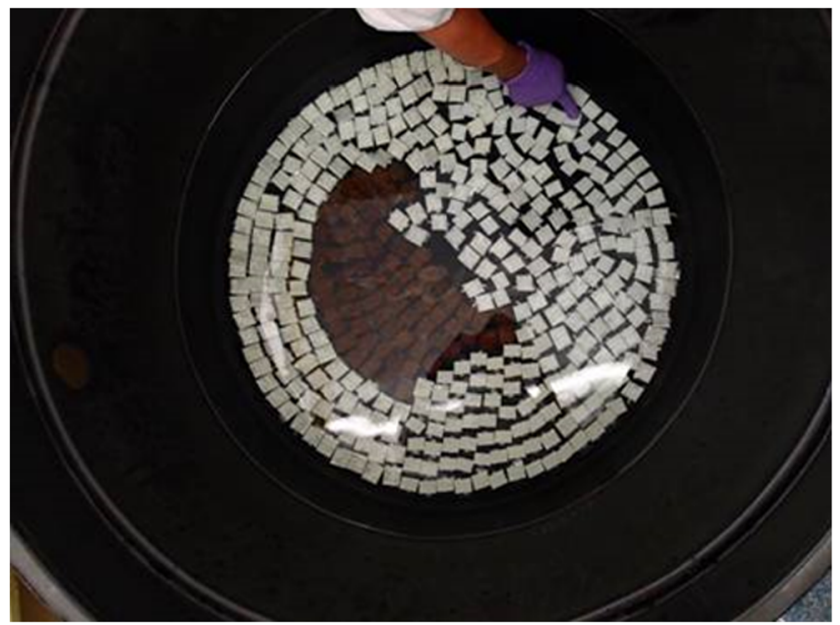

Fig. 2 Zygote settlement was conducted simultaneously on all materials tested. Glass slides wrapped with $24 \times 24 \mathrm{~mm}$ area of settlement twine were placed on the bottom of a large tank. The non-motile germlings were then allowed to settle
(WH7016, WILLHI, China) linked to a thermocouple and $100-200 \mathrm{~W}$ water heaters. Lighting was provided by overhead fluorescent lights (cool white $40 \mathrm{~W}$, Philips). Each tub was bubbled gently with lab air during the first week, with stronger aeration provided for the remaining period. The settlement slides were cultured for 8 weeks, with weekly media refreshment.

The Tyndallised seawater used was supplemented to test the effect of additional nutrients and $\mathrm{GeO}_{2}$. The conditions tested were unenriched seawater, enriched with $\mathrm{F} / 2-\mathrm{Si}$, and enriched with $\mathrm{F} / 2-\mathrm{Si}$ and $\mathrm{GeO}_{2}$ for the first week and enriched with $\mathrm{F} / 2-\mathrm{Si}$ and $\mathrm{GeO}_{2}$ throughout the whole experiment.

At the start of the experiment and each week, a photograph of each slide was analysed in ImageJ software v1.46r (National Institutes of Health, USA). The germling density was determined, survival rate was calculated and the length of 10 germlings was recorded.

\section{Statistical testing}

Minitab v.15 (Minitab Inc) and Excel 2010 (Microsoft) were used for statistical calculations. One-way (AN) and two-way analysis of variance ( $2 \mathrm{wAN}$ ), where significant, were followed by post-hoc Tukey's tests for comparisons between conditions. Parametric assumptions were evaluated and data transformed as necessary to fit these assumptions. Linear regression (LR) was used when a linear relationship was predicted.

\section{Results}

\section{Morphological variation of germlings}

At liberation, germlings had a diameter of $125 \pm 5 \mu \mathrm{m}$ and length of $195 \pm 5 \mu \mathrm{m}$ (Fig. 5). Following settlement, the germlings develop rapidly, forming an erect shoot axis and the basal production of eight transparent tubular rhizoids. After 3 days, the rhizoids had a mean length of $314 \pm$ $25 \mu \mathrm{m}$, attaching the germlings firmly to the settlement slides. After 1 week further basal rhizoids were produced, and the germlings had a length of 320-650 $\mu \mathrm{m}$ and 1-4 apical hairs 


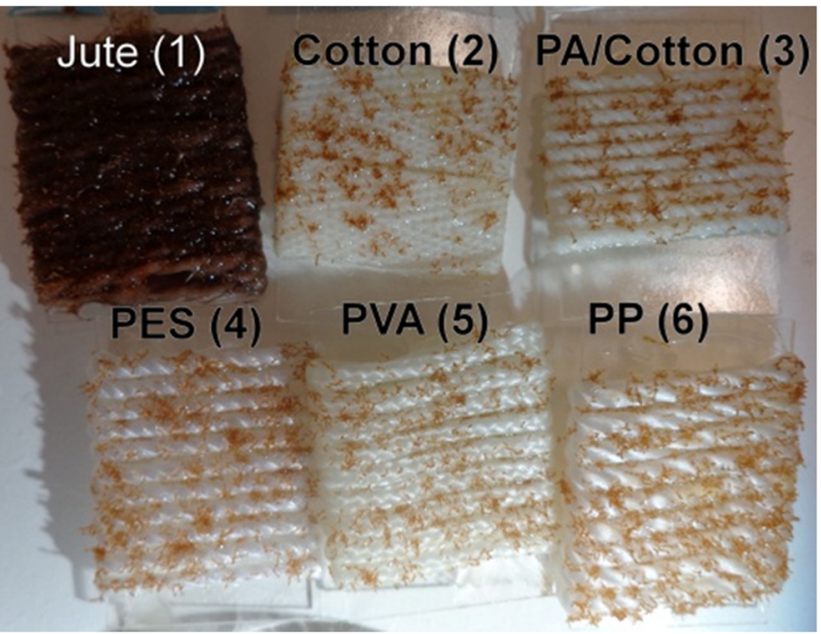

Fig. 3 Six twines were tested for their suitability for the cultivation of S. muticum. For each, a $\sim 24 \times 24 \mathrm{~mm}$ area was presented for their settlement. Shown are twines at week 6 with attached germlings

900-1200 $\mu \mathrm{m}$ composed of long columnar cells. In week 5, germling attained a length of about $1 \mathrm{~mm}$. By week 6, when 1.2-1.3-mm long, a small basal bud was produced which developed into the leaf-like lamina. At week 8, more laminae were produced, whilst numerous secondary rhizoids coalesced to form the holdfast.

\section{Germling growth and density over 8 weeks}

The growth rate was initially high in all conditions $(105 \pm$ $32 \%$ week $\left.^{-1}\right)$, declining exponentially $\left(y=618.9 \mathrm{e}^{-1.342 \mathrm{x}}\right.$, $R^{2}=0.93$ ) to $6 \pm 5 \%$ week $^{-1}$ during weeks 5 and 6 . Over the last 2 weeks, growth rate increased again to $17 \pm 42 \%$ week $^{-1}$ (Fig. 6a). Incremental growth was initially $21 \pm 6 \mu \mathrm{m} \mathrm{week}^{-1}$, declined to only $2 \pm 6 \mu \mathrm{m}$ week $^{-1}$ during weeks 5 and 6 , then increased again to $28 \pm 12 \mu \mathrm{m} \mathrm{week}^{-1}$ in weeks 7 and 8 (Fig. 6b).

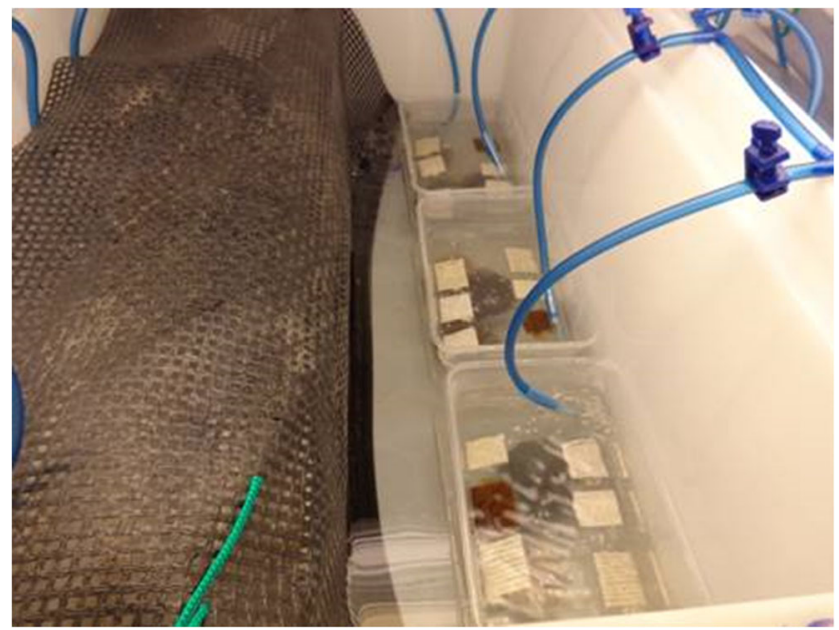

Fig. 4 The twines were cultivated in triplicate tubs $(400 \mathrm{~mL})$ at a set temperature within a water bath. Each tub was bubbled gently
The estimated frond area underwent a similar pattern, with area increasing from initially 0.08 to $0.5 \mathrm{~mm}^{2}$ in week 6 and then undergoing a rapid increase to $2.1 \mathrm{~mm}^{2}$ by week 8 (Fig. 6c). At settlement, the density was $240 \pm 14$ germlings $\mathrm{cm}^{2}$ (Fig. 6d). This declined linearly, at a rate of -32.7 germlings $\mathrm{cm}^{-2}$ week $^{-1}$ until week $5\left(r^{2}=0.98, n=18\right)$. From weeks $5-8$, this rate was only -8.9 germlings $\mathrm{cm}^{-2}$ week $^{-1}$. The density at week 8 was $53 \pm 5$ germlings $\mathrm{cm}^{-2}$, a 4.5-fold decrease from the settlement value.

\section{Effect of $\mathrm{F} / 2-\mathrm{Si}$ medium and $\mathrm{GeO}_{2}$}

Nutrient supplementation was not necessary for the optimal growth of $S$. muticum germlings. The rate of growth of germlings cultured in either $\mathrm{F} / 2$-Si or only seawater was not significantly different $(p>0.05)$ and followed a near identical growth trajectory over the 8-week experiment (Fig. 7). Treatment with $0.125 \mathrm{~mL} \mathrm{~L}^{-1}$ of saturated $\mathrm{GeO}_{2}$ appeared to slightly depress growth over the first 4 weeks. By the end of the experiment, a continual exposure of $\mathrm{GeO}_{2}$ had not significantly affected growth $(p>0.05)$ compared to the control. On the other hand, after 8 weeks, the germlings exposed to $\mathrm{GeO}_{2}$ for only the first 7 days were significantly larger by $23 \%$ (AN: $F_{1,8=} 17.1, p<0.005 ; 2.04 \pm 0.15 \mathrm{~mm}$ vs. $1.66 \pm 0.14 \mathrm{~mm}$ in the control).

\section{Germling density and size of the six twines}

On all materials, germling density declined over the course of the experiment (Fig. 8a). Jute retained the highest density by the end of the experiment of $81 \pm 16$ germling $\mathrm{cm}^{-2}$, significantly different from all others (ANOVA: $F_{5,18}=16.5$, $p<0.0001)$ which had $49 \pm 4$ germling $\mathrm{cm}^{-2}(p>0.05)$. There did appear to be a difference in the initial retention of the germlings between the materials. The rougher, natural, materials, jute and cotton had the highest successful attachment after 1 week (92-96\%). PA/cotton and PP had 79-81\% whilst PVA and PES had the lowest at 55-66\%. Following the first week, the density of surviving germlings declined fairly steadily on all materials (Fig. 8b). At week 8 , the highest survival was seen on either jute or PVA (35-36\%). Thereafter, these declined at 9.9 and 10.1 germling $\mathrm{cm}^{-2}$ week $^{-1}$, respectively (LR, $\left.r^{2}=0.93-0.98\right)$. On the other materials, $11.1 \%$ germling $\mathrm{cm}^{-2}$ were lost per week (LR, $\left.r^{2}=0.93\right)$, resulting in a lower final survival at week 8 (23-29\%).

The final germling size on the different substrates varied, with lower growth seen on jute $(1.06 \pm 0.14)$ than other twines $(1.38 \pm 0.06)$. When the final density was considered, there was a clear negative density-dependent effect $\left(R^{2}=0.84\right)$. The largest germlings were seen at the lower densities, and the smaller germlings were found at the highest densities on jute (Fig. 9). 

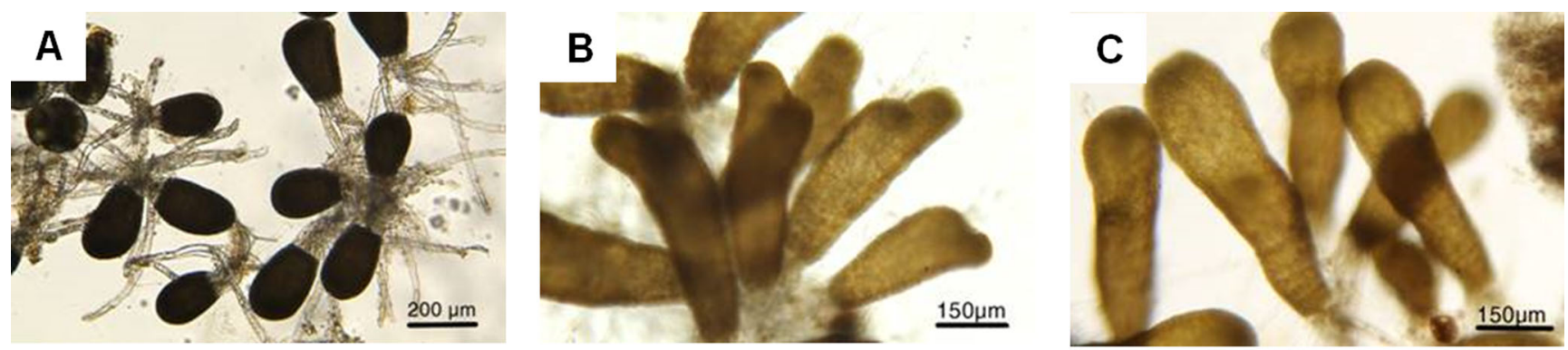

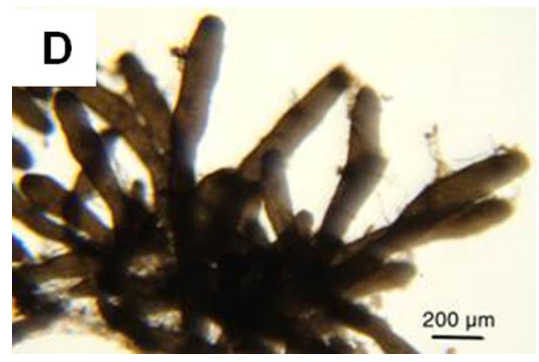

Fig. 5 The development of Sargassum muticum germlings over 8 weeks. a On the 3rd day following zygote release from the adults, eight transparent rhizoids were clearly visible. b After 1 week, c 2 weeks and d 4 weeks, germlings were growing rapidly, with further basal rhizoids

\section{Discussion}

By manipulating the hatchery conditions used in the cultivation of a macroalga, the survival and development rate of juveniles can be maximised before outplanting. Resource efficiency can then be optimised by shortening the time needed and reducing wastage of juvenile material. In this study, we found that it took 8 weeks for the hatchery cultivation of
S. muticum to yield germlings of $1.5-2 \mathrm{~mm}$. At this size, they can be outplanted in the sea for cultivation as in related Sargassum spp. (Xie et al. 2013). The growth rate observed was similar to that observed in S. thunbergii (Zhao et al. 2008) but was slow when compared to many other cultivated Sargassaceae; $5 \mathrm{~mm}$ is reached in about a month by either S. vachellianum or S. fulvellum (Hwang et al. 2006; Chai et al. 2014). The growth rate was also low in comparison
Fig. 6 Growth characteristics of Sargassum muticum germlings over 8 weeks. The weekly growth rate as either $\mathbf{a} \% \mathrm{wk}^{-1}, \mathbf{b} \mu \mathrm{m}$ $\mathrm{wk}^{-1}$ or $\mathbf{c}$ bladelet area. Also shown is $\mathbf{d}$ the decline in germling density due to detachment or death. Shown is mean \pm standard deviation. * denotes week pairs where growth was derived from a single measurement
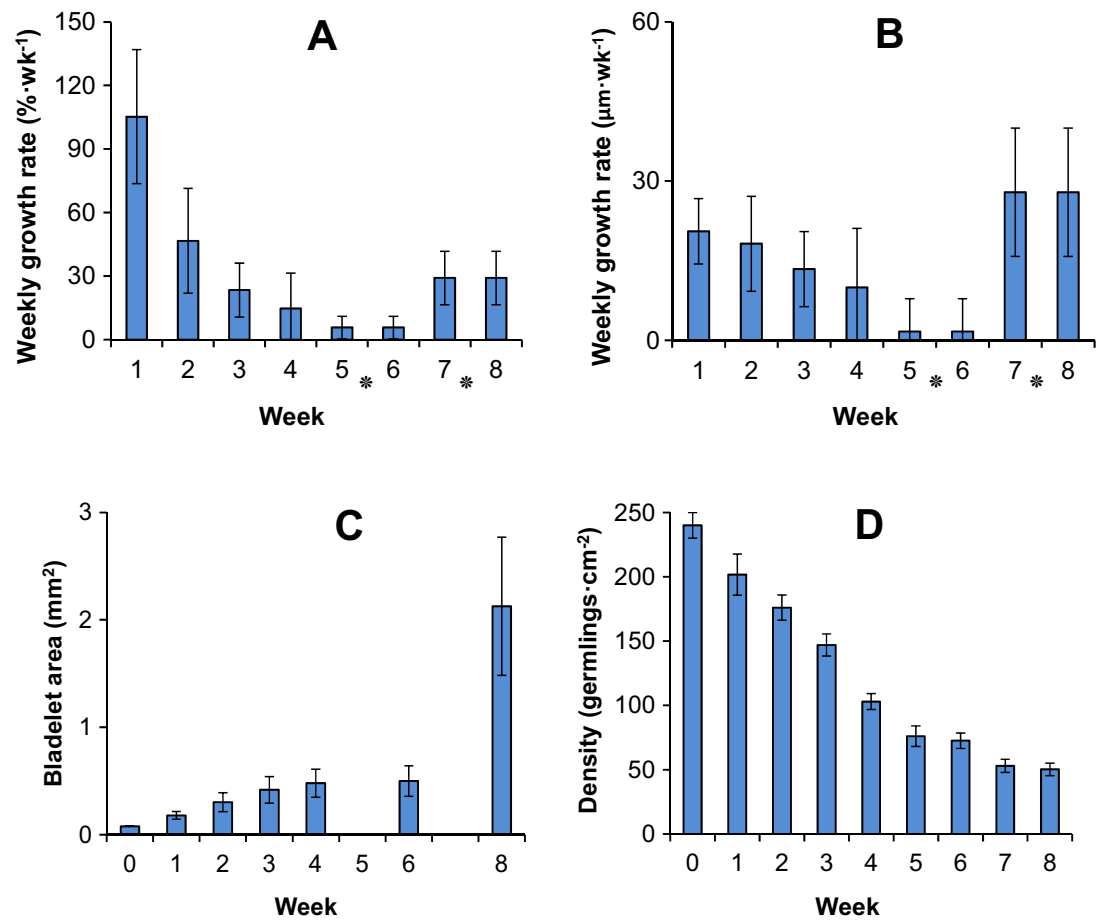


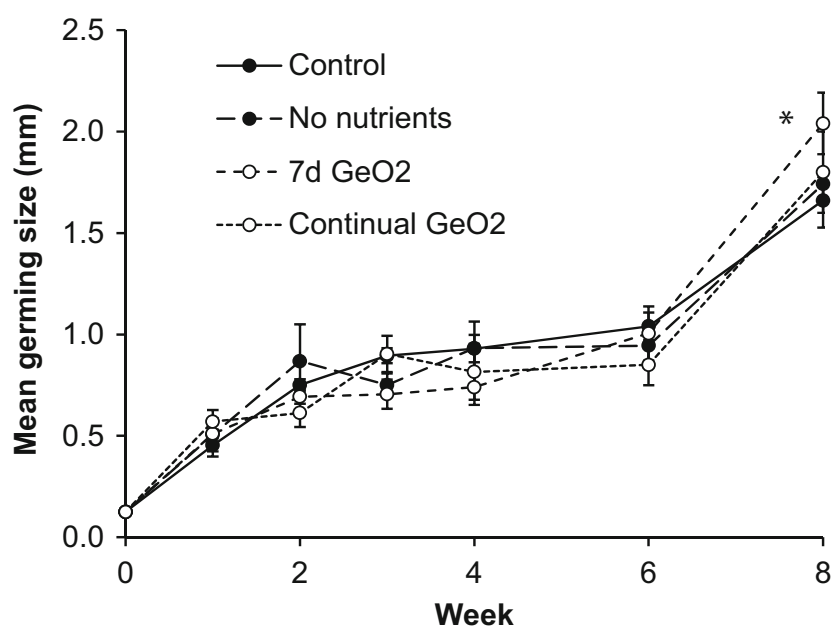

Fig. 7 Mean germling size of over an 8-week experiment under four experimental conditions. Control: F/2-Si medium. No nutrients: seawater only. $7 \mathrm{~d} \mathrm{GeO}_{2}: 0.125 \mathrm{~mL}$ of saturated $\mathrm{GeO}_{2} \mathrm{~L}^{-1}$ for the first 7 days of culture. Continual $\mathrm{GeO}_{2}: \mathrm{GeO}_{2}$ added throughout the experiment which was significantly different to the others at week $8\left({ }^{*} p<0.005\right)$. Shown is the mean \pm standard deviation
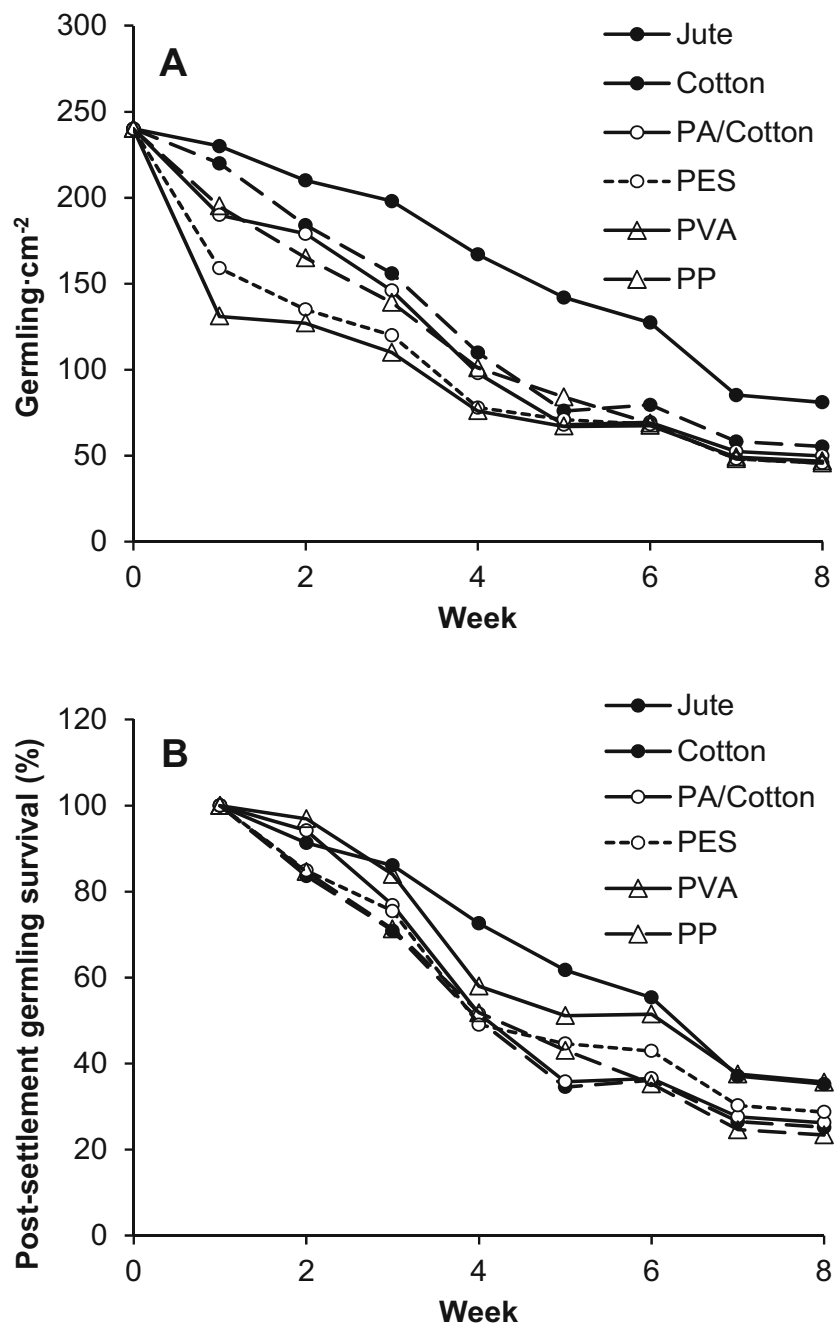

Fig. 8 a Density of S. muticum germlings on six different twines over the course of the 8-week experiment. b \% survival of germlings from weeks $1-8$. Shown is mean, no error bars are shown for clarity

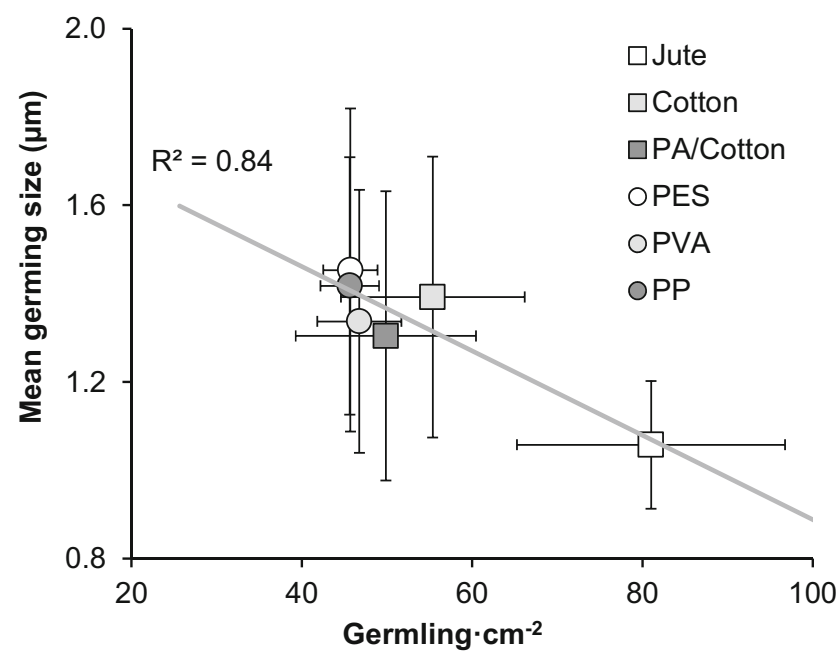

Fig. 9 Density dependence between mean germling size of S. muticum at week 8 and the germling density across the six materials. Shown is the mean \pm standard deviation

to other studies on S. muticum where 3-5 mm was achieved in a month post-settlement (Hales and Fletcher 1989; Steen 2004).

The reason for this slow growth was very likely due to the sub-optimal density used in this study. At high densities, intraspecific competition for resources such as light, $\mathrm{CO}_{2}$ or nutrients becomes intense. This resource limitation reduces the overall mean growth achieved by a population, leads to a large size inequity with the most successful individuals growing far larger than the majority of their compatriots. Also, selfthinning occurs as overgrowth leads to high mortality in the smaller individuals (Creed et al. 1998). When the density is low, each individual has sufficient resources, leading to fast growth, high survival and more similarly sized individuals across the whole population. This effect has been reported before in juvenile seaweeds (Reed et al. 1991; Steen and Scrosati 2004), including S. muticum, where it was found that germlings settled at $100 \mathrm{~cm}^{-2}$ had half the bladelet area of those settled at 10 germling $\mathrm{cm}^{-2}$ (Huggett et al. 2009). The initial density used in this study of $240 \pm 10$ germling $\mathrm{cm}^{-2}$ is far higher than the 20-65 germling $\mathrm{cm}^{-2}$ typically used in other Sargassum spp. experiments (McGuinness and Underwood 1986; McGuinness 1989; Hwang et al. 2006; Xie et al. 2013). This will have slowed the overall growth and increased mortality through intraspecific competition.

Very low densities will lead to even faster growth, as demonstrated in Steen (2003), where S. muticum cultured at 10 petridish $^{-1}$ reached $10 \mathrm{~mm}$ after 36 days. However, within a hatchery, very low densities will lead to open substratum available for the colonisation of contaminating organisms such as other macroalgae. These will then cause interspecific competition for resources during the early development of the germlings. Therefore, it has been recommended that about 20 germling $\mathrm{cm}^{-2}$ is the minimum density for commercial 
production of the Sargassaceae (McGuinness 1989; Lüning and Pang 2003).

The developmental stages of $S$. muticum over the 8-week experiment agree with a previous description of germling growth given by Fletcher and Fletcher (1975) and are similar to those seen in other members of the Sargassaceae (Zhao et al. 2008; Xie et al. 2013). The rate at which germling length increased, slowed over the first 6 weeks from an incremental growth rate of 21 to only $2 \mu \mathrm{m}$ week $^{-1}$. This appears to be due to the switch in the development from growing in frond length to the development of basal buds and lateral lamina, by week 6 and rhizoid holdfast expansion by week 8 . This spreading development was not captured by the weekly growth rate statistics, which was only based on germling length, leading to us underestimating the growth rate as these features developed. During weeks 6-8, the incremental growth rate and estimated bladelet area were seen to rapidly increase as length extension begins to accelerate again.

The first aim of this study was to determine whether supplementation of the growth medium with either nutrients or $\mathrm{GeO}_{2}$ could speed up the time taken for $\mathrm{S}$. muticum germlings to reach an outplantable size. In many studies, nutrient media are enriched by $\mathrm{KNO}_{3}$ and $\mathrm{KH}_{2} \mathrm{PO}_{4}$ to concentrations of 10 and $1 \mathrm{mg} \mathrm{L}^{-1}$, respectively (McGuinness 1989). We tested F/2-Si medium which is known to be very suitable for the growth of many algae. The Tyndallised seawater we used contained low concentrations of inorganic nutrients at this time of year, $2.3 \pm$ $0.3 \mu \mathrm{M}$ nitrate and $0.2 \pm 0.0 \mu \mathrm{M}$ phosphate. Despite the enrichment of inorganic $\mathrm{N}$ and $\mathrm{P}$ by 8.2 and $0.36 \mathrm{mM}$, respectively, no benefit was seen to the growth size or development rate, and so additional nutrients were not necessary over the first 8 weeks. This appeared sufficient for the first 8 weeks of $S$. muticum cultivation. It may be that $S$. muticum germlings contain sufficient nutrient stores to fuel growth over this initial period allowing its development to be maintained regardless of the environmental nutrient concentration. This would be advantageous for an opportunistic space-grabbing species such as this. This contrasts with the results of Steen (2003), where germling growth was found to be significantly stimulated by nutrient enrichment compared to autoclaved seawater with similarly low concentrations of nutrients to this study. This discrepancy may be due to a difference in the initial nutrient quotient of S. muticum eggs from the two populations, Scotland (this study) or Norway (Huggett et al. 2009).

The overgrowth of juvenile macroalgae by fast-growing benthic diatoms can lead to complete elimination, patchy development or slowed growth (Kerrison, $\mathrm{P}$, unpublished results). $\mathrm{GeO}_{2}$ is known to interfere with the formation of the diatom's frustule causing growth inhibition (Lewin 1966) but can also inhibit phaeophyte macroalgae at higher concentrations (Markham and Hagmeier 1982). Fucus spiralis was found to suffer some growth inhibition at only $0.2 \mathrm{mg} \mathrm{L}^{-1}$, equivalent to only $0.04 \mathrm{~mL}$ of saturated $\mathrm{GeO}_{2}$ solution per L. Concentrations of $0.1-0.5 \mathrm{~mL}$ of saturated $\mathrm{GeO}_{2}$ solution per $\mathrm{L}$ have been shown to be effective to improve development in the kelp S. latissima; however, higher concentrations inhibit its growth (Shea and Chopin 2007). Supplementation of the S. muticum medium with $0.125 \mathrm{~mL} \mathrm{~L}^{-1}$ over the first week of cultivation resulted in $23 \%$ larger germlings, whereas continual treatment over 8 weeks gave no benefit. This is a similar treatment regime to that found optimal for the hatchery phase of $S$. latissima (Kerrison et al. 2016b). Therefore, this treatment appears suitable for a wide range of phaeophyte macroalgae.

In the second aim, six materials were tested for their suitability as growth substrata for S. muticum germlings. After 8 weeks, all materials, both natural and synthetic, were successfully colonised by the developing germlings and so are suitable substrates for the hatchery cultivation of $S$. muticum. Germlings on all materials displayed very similar survival over weeks 1-8 ( 90\% week $\left.{ }^{-1}\right)$ indicating that the attachment tenacity was similar, although very slightly higher on jute and PVA. It appears that the adhesive and spreading rhizoids of S. muticum germlings are very effective at attaching to various substrata. This agrees with its invasive ecology as a successful opportunistic space-grabber, able to colonise any available hard surface (Fletcher and Fletcher 1975; Norton 1977; Denny 1988).

PVA and PES twines had the highest week 1 losses of 34 $55 \%$ of germlings, indicating that a weaker initial attachment was formed. In contrast, both jute and cotton only lost 4-8\% of the settled germlings during this time. It is thought that the rougher surface of these natural materials was beneficial to the initial attachment, through physical entanglement of the germlings in the fibres. This agrees with previous reports that generally, rugose surfaces are more favourable for settlement and attachment. Increasing the surface area for attachment, allowing physical interlocking and providing microenvironments that shield juveniles from high flow that can cause detachment (Malm et al. 2003; Morrison et al. 2009; Long et al. 2010). On the smoother synthetic fibres, entanglement would be less common reducing successful settlement.

On nearly all materials, by week 8 , the germling density had decreased to $49 \pm 4$ germling $\mathrm{cm}^{-2}$. Self-thinning of the population is most likely to be responsible (Creed et al. 1998) as the most successful individuals dominate and suppress the growth of smaller individuals (Steen and Scrosati 2004; Huggett et al. 2009). On jute, the final density was higher ( $81 \pm 4$ germling $\left.\mathrm{cm}^{-2}\right)$; however, the germlings were smaller and had more limited rhizoid development (data not shown). These characteristics are similar to those seen at week 6 on all other materials, indicating that the higher germling density retained by jute led to more intensive intraspecific competition and a slower overall development rate. Therefore, whilst it may initially appear, the jute is less suitable as a substrate due to slower growth, this is an artefact of higher germling density. 


\section{Conclusions}

Over an 8-week study on the cultivation of $S$. muticum germlings, we found that it was beneficial to add $0.125 \mathrm{~mL}$ $\mathrm{L}^{-1}$ of saturated $\mathrm{GeO}_{2}$ during the first week to inhibit the growth of diatom competitors. However, this benefit was lost if $\mathrm{GeO}_{2}$ was always added. Adding nutrients in the form of $\mathrm{F} /$ 2-Si did not give any benefit to growth indicating that the zygotes carried sufficient nutrient reserves to reach $\sim 2 \mathrm{~mm}$. If larger germlings are required, nutrient dosing may be necessary once they are beyond this size. It was also determined that various twines are suitable for the attachment and cultivation of S. muticum, with rougher natural materials leading to higher initial settlement success. Jute retained the highest density of germlings at settlement making it highly suitable for cultivation. However, care must be taken to control the initial settlement density. In this study, higher germling densities lead to slower growth due to intraspecific competition. An initial density of $\sim 20$ germling $\mathrm{cm}^{-2}$ is recommended as is used for other members of the Sargassaceae.

Contributors HNL, PDK and ADH designed the study. HNL and PDK carried out the experiment, analysed the data and wrote the manuscript. $\mathrm{HNL}, \mathrm{PDK}$ and $\mathrm{ADH}$ revised the manuscript and approved the final article.

Funding Funding was provided by a Researcher Links Travel Grant from the British Council (App ref: 127401486) to Hau Nhu Le and Philip D Kerrison. The funder was not involved in the experiment design, analysis, writing or publication decision.

\section{Compliance with ethical standards}

Conflict of interests The authors declare that they have no conflict of interest.

Open Access This article is distributed under the terms of the Creative Commons Attribution 4.0 International License (http:// creativecommons.org/licenses/by/4.0/), which permits unrestricted use, distribution, and reproduction in any medium, provided you give appropriate credit to the original author(s) and the source, provide a link to the Creative Commons license, and indicate if changes were made.

\section{References}

Al-Hafedh YS, Alam A, Buschmann AH (2015) Bioremediation potential, growth and biomass yield of the green seaweed, Ulva lactuca in an integrated marine aquaculture system at the Red Sea coast of Saudi Arabia at different stocking densities and effluent flow rates. Rev Aquac 7:161-171

Bitton R, Ben-Yehuda M, Davidovich M, Balazs Y, Potin P, Delage L, Colin C, Bianco-Peled H (2006) Structure of algal-born phenolic polymeric adhesives. Macromol Biosci 6:737-746

Callow ME, Callow JA, Ista LK, Coleman SE, Nolasco AC, López GP (2000) Use of self-assembled monolayers of different wettabilities to study surface selection and primary adhesion processes of green algal (Enteromorpha) zoospores. Appl Environ Microbiol 66: 3249-3254

Cao SQ, Zhang ZY, Wang GS, You XC, Liu HY (2008) Indoor artificial seeding of seaweed Sargassum muticum. J Dalian Fish Univ 23: 359-363

Chai Z, Huo Y, He Q, Huang X, Jiang X, He P (2014) Studies on breeding of Sargassum vachellianum on artificial reefs in Gouqi Island, China. Aquaculture 424-425:189-193

Cheang CC, Chu KH, Fujita D, Yoshida G, Hiraoka M, Critchley A, Choi HG, Duan D, Serisawa Y, Ang PO (2010) Low genetic variability of Sargassum muticum (Phaeophyceae) revealed by a global analysis of native and introduced populations. J Appl Phycol 46:1063-1074

Coston-Clements L, Settle LR, Hoss DE, Cross FA (1991) Utilization of the Sargassum habitat by marine invertebrates and vertebrates - a review. NOAA Tech Memo NMFS-SEFSC-296:32

Creed JC, Kain JM, Norton TA (1998) An experimental evaluation of density and plant size in two large brown seaweeds. J Phycol 34:39 52

Critchley AT, Farham WF, Morerell SL (1983) A chronology of new European sites of attachment for the invasive brown alga, Sargassum muticum 1973-81. J Mar Biol Assoc UK 63:799-811

Denny M (1988) Biology and the mechanics of the wave-swept environment. Princeton University Press, Princeton, p 344

Dexter SC, Sullivan JD, Williams J, Watson SW (1975) Influence of substrate wettability on the attachment of marine bacteria to various surfaces. Appl Microbiol 30:298-308

Fletcher RL, Fletcher SM (1975) Studies on the recently introduced brown alga Sargassum muticum (Yendo) Fensholt I. Ecology and reproduction. Bot Mar 18:149-156

Guillard RRL (1975) Culture of phytoplankton for feeding marine invertebrates. In: Smith WL, Chanley MH (eds) Culture of marine invertebrate animals. Plenum Press, New York, pp 26-60

Hales JM, Fletcher RL (1989) Studies on the recently introduced brown alga Sargassum muticum (Yendo) Fensholt. IV The effect of temperature, irradiance and salinity on germling growth. Bot Mar 32: $167-176$

Harries DB, Cook E, Donnan DW, Mair JM, Harrow S, Wilson JR (2007) The establishment of the invasive alga Sargassum muticum on the west coast of Scotland: rapid northwards spread and identification of potential new areas for colonisation. Aquat Invasions 2:367-377

Heydt M, Pettitt ME, Cao X, Callow ME, Callow JA, Grunze M, Rosenhahn A (2012) Settlement behavior of zoospores of Ulva linza during surface selection studied by digital holographic microscopy. Biointerphases 7:1-7

Hong DD, Hien HM, Son PN (2007) Seaweeds from Vietnam used for functional food, medicine and biofertilizer. J Appl Phycol 19:817826

Huggett MJ, Nedved BT, Hadfield MG (2009) Effects of initial surface wettability on biofilm formation and subsequent settlement of Hydroides elegans. Biofouling 25:387-399

Hwang EK, Park CS, Baek JM (2006) Artificial seed production and cultivation of the edible brown alga, Sargassum fulvellum (Turner) C. Agardh: developing a new species for seaweed cultivation in Korea. J Appl Phycol 18:251-257

Kawachi M, Noël M-H (2005) Sterilisation and sterile technique. In: Andersen RA (ed) Algal culturing techniques. Elsevier. Academic, London, pp 65-82

Kerrison P, Le HN (2016) Environmental factors on egg liberation and germling production of Sargassum muticum. J Appl Phycol 28: 1169-1180

Kerrison PD, Le HN, Twigg GC, Smallman DR, MacPhee R, Houston FAB, Hughes AD (2016a) Decontamination treatments to eliminate problem biota from tank cultures of Osmundea pinnatifida (Rhodophyta), Palmaria palmata (Rhodophyta) and Ulva lactuca (Chlorophyta). J Appl Phycol 28:3423-3434 
Kerrison PD, Stanley MS, Kelly M, Macleod A, Black KD, Hughes AD (2016b) Optimising the settlement and hatchery culture of Saccharina latissima (Phaeophyta) by manipulation of growth medium and substrate surface condition. J Appl Phycol 28:1181-1191

Lewin JC (1966) Silicon metabolism in diatoms V. Germanium dioxide, a specific inhibitor of diatom growth. Phycologia 6:1-12

Liu F, Pang S, Gao S, Shan T (2013) Intraspecific genetic analysis, gamete release performance, and growth of Sargassum muticum (Fucales, Phaeophyta) from China. Chin J Oceanol Limnol 31: $1268-1275$

Long CJ, Finlay JA, Callow ME, Callow JA, Brennan AB (2010) Engineered antifouling microtopographies: mapping preferential and inhibitory microenvironments for zoospore attachment. Biofouling 26:941-952

Lüning K, Pang S (2003) Mass cultivation of seaweeds: current aspects and approaches. J Appl Phycol 15:115-119

Malm T, Kautsky L, Claesson T (2003) The density and survival of Fucus vesiculosus L. (Fucales, Phaeophyta) on different bedrock types on a Baltic Sea moraine coast. Bot Mar 46:256-262

Markham JW, Hagmeier E (1982) Observations on the effects of germanium dioxide on the growth of macro-algae and diatoms. Phycologia 21:125-130

Mata L, Magnusson M, Paul NA, de Nys R (2016) The intensive landbased production of the green seaweeds Derbesia tenuissima and Ulva ohnoi: biomass and bioproducts. J Appl Phycol 28:365-375

McGuinness KA (1989) Effects of some natural and artificial substrata on sessile marine organisms at Galeta reef, Panama. Mar Ecol Prog Ser 52:201-208

McGuinness KA, Underwood AJ (1986) Habitat structure and the nature of communities on intertidal boulders. J Exp Mar Biol Ecol 104:97123

Morrison L, Feely M, Stengel DB, Blamey N, Dockery P, Sherlock A, Timmins É (2009) Seaweed attachment to bedrock: biophysical evidence for a new geophycology paradigm. Geobiology 7:477-487

Norton TA (1977) Ecological experiments with Sargassum muticum. J Mar Biol Assoc UK 57:33-43

Norton TA (1980) Sink, swim or stick: the fate of Sargassum muticum propagules. Br Phycol J 15:197-198

Norton TA, Fetter R (1981) The settlement of Sargassum muticum propagules in stationary and flowing water. J Mar Biol Assoc UK 61: 929-940

Pang SJ, Chen LT, Zhuang DG, Fei XG, Sun JZ (2005) Cultivation of the brown alga Hizikia fusiformis (Harvey) Okamura: enhanced seedling production in tumbled culture. Aquaculture 245:321-329

Pang SJ, Liu F, Shan TF, Gao SQ, Zhang ZH (2009) Cultivation of the brown alga Sargassum horneri: sexual reproduction and seedling production in tank culture under reduced solar irradiance in ambient temperature. J Appl Phycol 21:413-422

Redmond S, Kim JK, Yarish C, Pietrak M, Bricknell I (2014) Culture of Sargassum in Korea: techniques and potential for culture in the U.S. Orono, ME: Maine Sea Grant College Program at the University of Maine. seagrant.umaine.edu/extension/korea-aquaculture

Reed DC, Neushul M, Ebeling AW (1991) Role of settlement density on gametophyte growth and reproduction in the kelps Pterygophora californica and Macrocystis pyrifera (Phaeophyceae). J Phycol 27: 361-366

Shea R, Chopin T (2007) Effects of germanium dioxide, an inhibitor of diatom growth, on the microscopic laboratory cultivation stage of the kelp, Laminaria saccharina. J Appl Phycol 19:27-32

Sohn CH (1993) Porphyra, Undaria and Hizikia cultivation in Korea. Algae 8:207-216

Steen H (2003) Intraspecific competition in Sargassum muticum (Phaeophyceae) germlings under various density, nutrient and temperature regimes. Bot Mar 436:36-43

Steen H (2004) Effects of reduced salinity on reproduction and germling development in Sargassum muticum (Phaeophyceae, Fucales). Eur J Phycol 39:293-299

Steen H, Scrosati R (2004) Intraspecific competition in Fucus serratus and $F$. evanescens (Phaeophyceae: Fucales) germlings: effects of settlement density, nutrient concentration, and temperature. Mar Biol 144:61-70

Strong JA, Dring MJ, Maggs CA (2006) Colonisation and modification of soft substratum habitats by the invasive macroalga Sargassum muticum. Mar Ecol Prog Ser 321:87-97

Titlyanov EA, Titlyanova TV, Pham VH (2012) Stocks and the uses of economic marine macrophytes of Vietnam. Russ J Mar Biol 38: 285-298

Tsukidate J (1992) Ecology of Sargassum spp. and Sargassum forest formation. NOAA Tech Rep NMES 106:63-72

Xie EY, Liu DC, Jia C, Chen XL, Yang B (2013) Artificial seed production and cultivation of the edible brown alga Sargassum naozhouense Tseng et Lu. J Appl Phycol 25:513-522

Yoon JT, Sun SM, Chung G (2014) Sargassum bed restoration by transplantation of germlings grown under protective mesh cages. J Appl Phycol 26:505-509

Yoshida T (1983) Japanese species of Sargassum subgenus Bactrophycus (Phaeophyta, Fucales). J Fac Sci Hokkaido Univ 13:99-246

Zhao Z, Zhao F, Yao J, Lu J, Ang PO, Duan D (2008) Early development of germlings of Sargassum thunbergii (Fucales, Phaeophyta) under laboratory conditions. J Appl Phycol 20:475-481 